\title{
Discrimination of Lonicera japonica and Lonicera confusa using chemical analysis and genetic marker
}

\author{
Jin Ah Ryuk", Hye Won Lee\#, Byoung Seob Ko* \\ KM-Based Herbal Drug Research Group, Korea Institute of Oriental Medicine
}

\begin{abstract}
Objective : Lonicera japonica THUNB. a traditional herbal medicine, has been commonly used anti-inflammatory disease. It has been very complicated with respect to its sources on the market. The significant selection of medicine depends on its origin. However, it is difficult to discrimination criteria for confirming $L$. japonica authenticity using the senses. This study was performed to determine the discriminant analysis of $L$. japonica and L. confusa.

Methods : The identification of $L$. japonica and $L$. confusa were performed by the classification and identification committee of the national center for standardization of herbal medicines. And we examined its differences using HPLC and genetic marker analysis.

Results : The analytical pattern of High Performance Liquid Chromatography was determined from the corresponding peak curves ((E)-aldosecologanin, chlorogenic acid, luteolin 7-O-glucoside, sweroside). For $L$. japonica, additional unknown peaks were detected at $13.8 \mathrm{~min}, 20.6 \mathrm{~min}$, and $36.9 \mathrm{~min}$. And, we developed genetic marker using the the tRNA-Leu gene, $\operatorname{trnL}-\operatorname{trnF}$ intergenic spacer and tRNA-Phe region of chloroplast DNA. By the method, 164 bp PCR product amplified from $L$. confusa was distinguished into $L$. japonica and $L$. confusa efficiently.

Conclusion : Base on these results, two techniques provide effective approaches to distinguish L. japonica from L. confusa.
\end{abstract}

Key words : Lonicera japonica, High Performance Liquid Chromatography, genetic marker, discrimination

\section{Introduction}

Lonicera japonica THUNB. (Caprifoliaceae) is commonly used as an anti-inflammatory herbal medicine $^{1)}$. It has been very complicated with respect to its sources on the market. Lonicerae Flos is of high medicinal value in traditional Chinese medicine, where it is called jīn yín huā (金銀花). The flowers are double-tongued, opening white and fading to yellow, and sweetly scented. It has antibacterial ${ }^{2)}$ and anti-inflammatory properties ${ }^{3,4)}$, and is used to dispel heat and remove toxins, including carbuncles, fevers, influenza and ulcers. Caprifoliaceae Lonicera confusa, shan yín huā (山銀花) in Chinese, is a woody vine, the distribution of the region wide in China's southwestern. The flowers have also been used on the same purpose in China ${ }^{5)}$. This plant has a much softer appearance than the more commonly used L. japonica.

In Korea Pharmacopeia, Lonicerae Flos is documented as the sources of origin plant ${ }^{6)}$. It is called geumeunhwa. So it is an important issue to comprehensively evaluate the different sources of $L$. japonica, so as to ensure the clinical efficacy of these herbal drugs. As the international trade is increased, the import of $L$. japonica from China to Korea has been growing.

Chemical and pharmacological investigations on

\footnotetext{
* Corresponding author : Byoung Seob Ko, KM-Based Herbal Drug Research Group, Korea Institute of Oriental Medicine

· Tel : +82-42-868-9542 · Fax +82-42-868-9293 · E-mail : bsko@kiom.re.kr

\# First author : Jin Ah Ryuk, KM-Based Herbal Drug Research Group, Korea Institute of Oriental Medicine

· Tel : +82-42-868-9509 · Fax +82-42-868-9509 ·E-mail : yukjinah@kiom.re.kr

First author : Hye Won Lee, KM-Based Herbal Drug Research Group, Korea Institute of Oriental Medicine

· Tel : +82-42-868-9506 · E-mail : hwlee@kiom.re.kr

·접수 : 2012년 10월 15일 · 수정 : 2012년 11월 3일 · 채택 : 2012년 11월 8일
} 
Lonicerae Flos resulted in discovering several kinds of bioactive components, i.e. chlorogenic acid and its analogues $^{7,8)}$, flavonoids ${ }^{9)}$, iridoid glucosides ${ }^{10,11)}$ and triterpenoid saponins ${ }^{12,13)}$.

Some closely related species of $L$. japonica which have similar morphology but weaker biological activity are also used medicinally. Because there are differences in the amount and distribution of constituents between $L$. japonica and $L$. confusa, the discrimination between the two species essential. The discrimination of $L$. japonica from its adulterants is currently limited to methods of morphology and chemical fingerprinting. So far, many studies have examined the constituents and efficacy of $L$. japonica and $L$. confusa, but molecular genetic reports have been not enough. Besides, with the discrimination based on the gross features such as shape or color reveal the limitation in differentiating between $L$. japonica and $L$. confusa. Noncoding regions of cpDNA are presumably under less functional constraints and evolve more rapidly, so they may provide useful phylogenetic information at lower taxonomical levels and offer molecular marker for species identification ${ }^{14)}$.

In this study, the chemical analysis of four compounds (Fig. 1) ${ }^{15)}$, namely: (E)-aldosecologanin, chlorogenic acid, luteolin 7-O-glucoside, sweroside, were used to qualitatively and quantitatively distinguish different origins of $L$. japonica and $L$. confusa. And, the analytical pattern of HPLC was determined from the corresponding peak curves. In addition, we could obtain a genetic marker between $L$. japonica and $L$. confusa from trnL-trnF sequences.
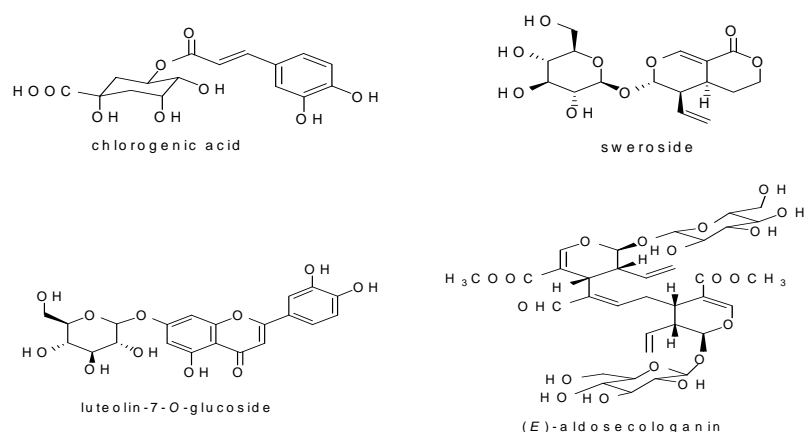

Figure 1. Chemical structures of standards.

\section{Materials and methods}

\section{Materials}

The materials were collected from fresh leaf and purchased from a commercial supplier in Korea and China (Table 1). Fresh leaves were only used as the method of genetic analysis. Samples were deposited in the herbarium of Korea Institute of Oriental Medicine.
The identification of species was performed by the classification and identification committee of the national center for standardization of herbal medicines.

Table 1. Plant materials of $L$. japonica and $L$. confusa

\begin{tabular}{|c|c|c|c|c|c|}
\hline No. & Species & Plant tissue & Code No. & \multicolumn{2}{|c|}{ Locality } \\
\hline 1 & & Fresh leaf & $89-1-01$ & Hamyang, & Korea \\
\hline 2 & & Fresh leaf & $89-1-04$ & Seongnam, & Korea \\
\hline 3 & & Fresh leaf & $89-1-06$ & Jeju, & Korea \\
\hline 4 & & Fresh leaf & $89-1-12$ & Jeonju, & Korea \\
\hline 5 & & Fresh leaf & $89-1-13$ & Jinan, & Korea \\
\hline 6 & & Fresh leaf & $89-1-14$ & Suwon, & Korea \\
\hline 7 & & Fresh leaf & $89-1-11$ & Yunnan, & China \\
\hline 8 & & Fresh leaf & $89-1-15$ & Anguk, & China \\
\hline 9 & & Dried flower & $\mathrm{G}-10-14$ & Andong, & Korea \\
\hline 10 & & Dried flower & $G-10-19$ & Hongcheon, & Korea \\
\hline 11 & & Dried flower & $\mathrm{G}-10-21$ & Goheung, & Korea \\
\hline 12 & & Dried flower & $G-10-22$ & Yangyang, & Korea \\
\hline 13 & & Dried flower & $\mathrm{G}-10-23$ & Bonghwa, & Korea \\
\hline 14 & L. japonica & Dried flower & $\mathrm{G}-10-24$ & Gangneung, & Korea \\
\hline 15 & & Dried flower & G-10-25 & Buyeo, & Korea \\
\hline 16 & & Dried flower & $G-10-26$ & Goheong, & Korea \\
\hline 17 & & Dried flower & $\mathrm{G}-10-27$ & Uiseong, & Korea \\
\hline 18 & & Dried flower & $G-10-28$ & Seorak, & Korea \\
\hline 19 & & Dried flower & $G-10-29$ & Cheongsong, & Korea \\
\hline 20 & & Dried flower & $\mathrm{G}-10-30$ & Gunwi, & Korea \\
\hline 21 & & Dried flower & $\mathrm{G}-10-31$ & Uljin, & Korea \\
\hline 22 & & Dried flower & G-10-02 & Henan, & China \\
\hline 23 & & Dried flower & $G-10-16$ & Shandong, & China \\
\hline 24 & & Driedflower & G-10-36 & Commercial $^{*}$ & Korea \\
\hline 25 & & Driedflower & $\mathrm{R}-\mathrm{LJ}-2$ & Commercial $^{*}$ & Korea \\
\hline 26 & & Driedflower & $\mathrm{R}-\mathrm{LJ}-3$ & Commercial $^{*}$ & Korea \\
\hline 27 & & Driedflower & R-LJ-6 & Commercial $^{*}$ & Korea \\
\hline 28 & & Dried flower & $\mathrm{S}-11-01$ & Commercial", & Korea \\
\hline 29 & L. confusa & Dried flower & $\mathrm{S}-11-02$ & Commercial", & Korea \\
\hline 30 & & Dried flower & $\mathrm{S}-11-03$ & Commercial", & Korea \\
\hline 31 & & Dried flower & $\mathrm{S}-11-04$ & Commercial", & Korea \\
\hline 32 & & Dried flower & $\mathrm{S}-11-05$ & Commercial", & Korea \\
\hline 33 & & Dried flower & $\mathrm{S}-11-06$ & Hebei, & China \\
\hline 34 & & Dried flower & $\mathrm{S}-11-07$ & Hebei, & China \\
\hline 35 & & Dried flower & $S-11-08$ & Hebei, & China \\
\hline 36 & & Dried flower & S-11-09 & Hebei, & China \\
\hline 37 & & Dried flower & $\mathrm{S}-11-10$ & Hebei, & China \\
\hline
\end{tabular}

: Be purchased in the herbs market.

\section{Instrument and reagents}

Agilent 1100 series HPLC instrument (Agilent Technologies, U.S.A.), equipped with a autosampler, column oven, binary pump, DAD detector and degasser was used. Data was acquired and processed by chemstation software (Agilent Technologies, U.S.A.). All the standards, (E)-aldosecologanin, chlorogenic acid, luteolin 7-O-glucoside and sweroside were provided by Prof. S. S. Kang, National Seoul University, 
Korea. Their purities were above $97 \%$ as determined by HPLC and LC MS/MS analysis.

\section{Sample and standard solution preparation for HPLC}

Sample preparation was as follows. Approximately $200 \mathrm{mg}$ of the flower buds were pulverized, accurately weighed, and then it was extracted exhaustively with 10 $\mathrm{mL}$ of $70 \%(\mathrm{v} / \mathrm{v})$ ethanol/water in ultrasonication for 2 $\mathrm{hr}$. The residue was re-dissolved in $10 \mathrm{~mL}$ of $70 \%$ (v/v) ethanol/water for HPLC analysis and then it was filled up to $20 \mathrm{~mL}$ with $70 \%(\mathrm{v} / \mathrm{v})$ ethanol/water. Four identified compounds of (E)-aldosecologanin, chlorogenic acid, luteolin 7-O-glucoside, and sweroside at the concentration of $2 \mathrm{mg} / \mathrm{mL}$ for each were prepared respectively by dissolving in $70 \%$ (v/v) ethanol. Each stock solution was diluted with $70 \%(\mathrm{v} / \mathrm{v})$ ethanol to create seven calibration points $(0.5,5,10,25,50$, 100 and $500 \mu \mathrm{g} / \mathrm{mL}$ ) for the preparation of the calibration curves. All solutions were filtered by a 0.45 um membrane filter unit prior to HPLC analysis, and were stable at least for 1 week when stored at $4^{\circ} \mathrm{C}$.

\section{Method validation}

The analytical method was validated with respect to the linearity, limit of detection (LOD), limit of quantification (LOQ), and repeatability. The linearity of detection for each analyte was determined using seven different standard solutions $(0.5,5,10,25,50$, 100 and $500 \mu \mathrm{g} / \mathrm{mL}$ ). A calibration was constructed by performing linear regression of peak area vs analyte concentration. The equations and linear ranges are listed in Table 3. The correlation coefficients (r2) of (E)-aldosecologanin, chlorogenic acid, luteolin 7-O-glucoside, and sweroside ranged 0.9991-0.9999. The limits of detection (LOD) and quantification (LOQ) under the chromatographic conditions were separately determined in six replicate determinations at a signal-to-noise ratio $(\mathrm{S} / \mathrm{N})$ of 3 . TheLODs $(\mathrm{S} / \mathrm{N}=3)$ and LOQs $(\mathrm{S} / \mathrm{N}=10)$ obtained for each standard were $0.010-0.075 \mu \mathrm{g} / \mathrm{mL}$ and $0.025-0.250 \mu \mathrm{g} / \mathrm{mL}$, respectively. Repeatability was described as the relative standard deviation (RSD) and was evaluated by analysing samples in triplicate. Mean RSDs of each compound for L. japonica (No. 9 27 of Table 1) and L. confusa (No. 28 37 of Table 1) were calculated (Table 4). The developed analytical method was subsequently applied to the simultaneous determination of the four components in Lonicera spp. extract. The contents of the analytes were determined from the corresponding calibration curves.

\section{HPLC condition}

The separation was carried out on a YMC-Pack Pro C18 (5 $\mu \mathrm{m}, 4.6 \mathrm{~mm} \times 150 \mathrm{~mm})$ and for gradient elution, $100 \%$ deionized water for A solvent and 100\% acetonitrile for B solvent, to which $0.1 \%$ formic acid was added respectively at $25^{\circ} \mathrm{C}$; the gradient program was used as follows: initial 0-10 min, linear change from A/B (85:15, v/v) to A/B (80:20, v/v); 10-20 min, linear change to $A / B(80: 20, \mathrm{v} / \mathrm{v}) ; 20-22 \mathrm{~min}$, linear change to $\mathrm{A} / \mathrm{B}(75: 25, \mathrm{v} / \mathrm{v}) ; 22-35 \mathrm{~min}$, linear change to $\mathrm{A} / \mathrm{B}(65: 35, \mathrm{v} / \mathrm{v}) ; 35-40 \mathrm{~min}$, linear change to $\mathrm{A} / \mathrm{B}(85: 15, \mathrm{v} / \mathrm{v})$. The flow rate was set at 0.3 $\mathrm{mL} / \mathrm{min}$ and the injection volume was $10 \mu$ (Table 2 ).

Table 2. Solvent gradient condition for HPLC-DAD

\begin{tabular}{cccc}
\hline $\begin{array}{c}\text { Final time } \\
(\mathrm{min})\end{array}$ & $\begin{array}{c}\text { Flow rate } \\
(\mathrm{mL} / \mathrm{min})\end{array}$ & $\mathrm{A}$ & $\mathrm{B}$ \\
\hline \hline 0 & 0.3 & 85 & 15 \\
10 & 0.3 & 80 & 20 \\
20 & 0.3 & 80 & 20 \\
22 & 0.3 & 75 & 25 \\
35 & 0.3 & 65 & 35 \\
40 & 0.3 & 85 & 15 \\
\hline
\end{tabular}

A : $\mathrm{H}_{2} \mathrm{O}$ with $0.1 \%$ formic acid,

$\mathrm{B}$ : Acetonitrile with $0.1 \%$ formic acid.

\section{Genomic DNA extraction}

The genomic DNA of each sample was extracted according to the manual for the DNeasy ${ }^{\circledR}$ plant Mini kit (QIAGEN, U.S.A.). DNA concentration and purity were determined by spectrophotometry (Nanodrop ND-1000, Nanodrop, U.K.), and electrophoresis in a $1.5 \%$ agarose gel with DNA size marker (TaKaRa, Japan). The final concentration of each sample was diluted to approximately $20 \mathrm{ng} / \mu \mathrm{l}$ with DEPC (diethyl pyrocarbonate)-DW for PCR amplification.

\section{PCR amplification of $\operatorname{trnL}-\operatorname{trn} F$ region, cloning, sequencing}

Primers trnL-trnF c (5'-CGA AAT CGG TAG ACG CTA CG-3') and trnF (5'-ATT TGA ACT GGT GAC ACG AG-3') described by Taberlet et al. ${ }^{16)}$ were used to amplify the trnL-trnF region of cpDNA. Total volume of $30 \mathrm{ul}$ reaction mixture contained $10 \mathrm{pmol} /$ ul of each primer, $2 \times$ premix (Solgent, Korea) and 20 ng template. Reactions were carried out with a PTC-200 (MJ Research, U.S.A.). The temperature cycling paramerters were programmed for on cycle of $5 \mathrm{~min}$. at $95^{\circ} \mathrm{C}$, followed by 35 cycles of $30 \mathrm{sec}$. at 9 $5{ }^{\circ} \mathrm{C}, 30 \mathrm{sec}$. at $55^{\circ} \mathrm{C}, 1 \mathrm{~min}$. at $72^{\circ} \mathrm{C}$, and on cycle of $4 \mathrm{~min}$. at $72^{\circ} \mathrm{C}$. PCR products with LoadingSTAR (DyneBio, Korea) were electrophoresed in 1.5\% agarose 
gel, with a 100 bp DNA size marker (TaKaRa, Japan) in Tris-borate EDTA buffer. The amplified DNA fragments was separated by gel electrophoresis from the agarose gel using the Gel extraction kit (Promega, U.S.A.). These fragments were then subcloned in to the pGEM T-easy vector (Promega, U.S.A.). The nucleotide sequences of the resulting inserted DNA fragments were determined by an automatic DNA sequencer (ABI, 3730 Applied Biosystems, U.S.A.). Sequence alignment analysis was conducted using the DNASTAR $^{\circledR}$ Lasergene $^{\circledR} \quad 7.2$ software (U.S.A.) and compared with data of NCBI (National Center for Biotechnology Information).

\section{Development of genetic markers}

We performed sequences alignment analysis of $L$. japonica and L. confusa and then designed the LJCF primer (5'-TTC ACG GTC AAT ATC ATT ATT CAT AC-3'), LJCR primer (5'-TTT ACT AGA TAA CTA GGG TCT ATG TC-3'), LCF primer (5'-ATT TCT CAT CCA CCT TAC TTT AC-3') and LCR primer (5'-TGA ATA ATG ATA TTG ACC GTG AAT C-3') on the species-specific site. Total volume of $30 \mu l$ reaction mixture contained $5 \mathrm{pmol} / \mu \ell$ of each primer, $2 \times$ premix (Solgent, Korea) and $20 \mathrm{ng}$ template. Reactions were carried out with a PTC-200 (MJ Research, U.S.A.). The temperature cycling paramerters were programmed for on cycle of $5 \mathrm{~min}$. at $95^{\circ} \mathrm{C}$, followed by 30 cycles of 20 sec. at $95^{\circ} \mathrm{C}, 30 \mathrm{sec}$. at $47^{\circ} \mathrm{C}, 60 \mathrm{sec}$. at $72^{\circ} \mathrm{C}$, and on cycle of $5 \mathrm{~min}$. at $72^{\circ} \mathrm{C}$. PCR products with LoadingSTAR (DyneBio, Korea) were electrophoresed in $2.0 \%$ agarose gel, with a 100 bp DNA size marker (TaKaRa, Japan) in Tris-borate EDTA buffer.

\section{Results}

\section{Method validation}

The analytical method was validated with respect to the linearity, limit of detection (LOD), limit of quantification (LOQ), and repeatability. The linearity of detection for each analyte was determined using seven different standard solutions (0.5, 5, 10, 25, 50, 100 and $500 \mu \mathrm{g} / \mathrm{mL}$ ). A calibration was constructed by performing linear regression of peak area vs analyte concentration. The equations and linear ranges are listed in Table 3. The correlation coefficients (r2) of (E)-aldosecologanin, chlorogenic acid, luteolin 7-O-glucoside, and sweroside ranged 0.9991-0.9999. TheLODs $(\mathrm{S} / \mathrm{N}=3)$ and LOQs $(\mathrm{S} / \mathrm{N}=10)$ obtained for each standard were $0.010-0.075 \mu \mathrm{g} / \mathrm{mL}$ and $0.025-0.250 \mu \mathrm{g} / \mathrm{mL}$, respectively. Repeatability was described as the relative standard deviation (RSD) and was evaluated by analysing samples in triplicate (Table 4).

Table 3. Linear range, linear equation, correlation coefficient, limits of detection (LOD), and limits of quantitation (LOQ) for standards

\begin{tabular}{|c|c|c|c|c|c|}
\hline Compounds & $\begin{array}{c}\text { Linearrange } \\
(\mu \mathrm{g} / \mathrm{mL})\end{array}$ & Linear equation & r2 & $\begin{array}{c}\text { LOD } \\
(\mu \mathrm{g} / \mathrm{mL})\end{array}$ & $\begin{array}{c}\text { LOQ } \\
(\mu \mathrm{g} / \mathrm{mL})\end{array}$ \\
\hline (E)-aldosecologanin & $0.5-500$ & $\begin{aligned} \mathrm{y}= & 51.6795 \mathrm{x}- \\
& 33.61\end{aligned}$ & 0.9999 & 0.010 & 0.025 \\
\hline Chlorogenic acid & $0.5-500$ & $\begin{aligned} \mathrm{y}= & 43.5509 \mathrm{x}- \\
& 299.69\end{aligned}$ & 0.9991 & 0.075 & 0.250 \\
\hline $\begin{array}{l}\text { Luteolin } \quad 7-\mathrm{O}- \\
\text { glucoside }\end{array}$ & $0.5-500$ & $\begin{array}{c}\mathrm{y}=66.626 \mathrm{x}- \\
275.65\end{array}$ & 0.9995 & 0.050 & 0.125 \\
\hline Sweroside & $0.5-500$ & $\begin{aligned} \mathrm{y}= & 52.4410 \mathrm{x}- \\
& 163.89\end{aligned}$ & 0.9997 & 0.025 & 0.050 \\
\hline
\end{tabular}

Table 4. Mean contents and RSDs of the identified compounds in $L$. japonica and L. confusa

\begin{tabular}{lcccccc}
\hline \multirow{2}{*}{ Compound } & \multicolumn{2}{c}{ L. japonica $^{\mathrm{a}}$} & & \multicolumn{2}{c}{ L. confusa } \\
\cline { 2 - 3 } \cline { 5 - 6 } & $\begin{array}{c}\text { Mean content Mean RSD } \\
(\mathrm{mg} / \mathrm{g})\end{array}$ & & \multicolumn{2}{c}{$\begin{array}{c}\text { Mean content Mean RSD } \\
(\mathrm{mg} / \mathrm{g})\end{array}$} & $(\%)$ \\
\hline \hline $\begin{array}{l}\text { (E)-aldosecologanin } \\
\text { Chlorogenic acid }\end{array}$ & $0.37 \pm 0.48$ & $3.02 \pm 2.40$ & & N.D.c & - \\
$\begin{array}{l}\text { Luteolin 7-O- } \\
\text { glucoside }\end{array}$ & $8.09 \pm 8.24$ & $5.83 \pm 3.86$ & & $33.14 \pm 6.74$ & $4.50 \pm 4.32$ \\
Sweroside & $0.99 \pm 0.30$ & $4.12 \pm 3.44$ & & $1.00 \pm 0.07$ & $4.77 \pm 2.91$ \\
\hline
\end{tabular}

a : No. 9 27 of Table 1, b : No. 28 37 of Table 1,

c : not detected.

\section{Quantitative analysis of the identified compounds}

A comparative analysis of HPLC-DAD pattern was performed for $L$. japonica and $L$. confusa under the condition where (E)-aldosecologanin, chlorogenic acid, luteolin 7-O-glucoside, and sweroside were used as identified compounds. The result of quantitative analysis is summarized in Table 4. The retention times of each identified compound were as follows; $14.9 \mathrm{~min}$ for chlorogenic acid; $17.8 \mathrm{~min}$ for sweroside; $31.5 \mathrm{~min}$ for luteolin 7-O-glucoside; and $34.7 \mathrm{~min}$ for (E)-aldosecologanin. For $L$. japonica, besides the aforementioned retention times, additional unknown peaks were detected at $13.8 \mathrm{~min}, 20.6 \mathrm{~min}$, and 36.9 min. Upon analysis, two identified compounds and two unknown peaks were detected in both species, in the order of; chlorogenic acid, $14.9 \mathrm{~min}$; unknown peak, $20.6 \mathrm{~min}$; luteolin 7-O-glucoside, $31.5 \mathrm{~min}$; and unknown peak, $36.9 \mathrm{~min}$. A further unknown peak at $13.8 \mathrm{~min}$, sweroside at $18.2 \mathrm{~min}$, and (E)-aldosecologanin at $34.7 \mathrm{~min}$, were only detected in L. japonica (Fig. 2). 


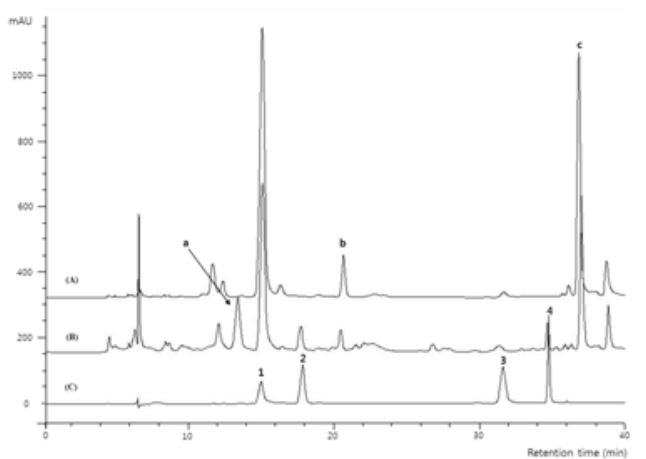

Figure 2. Chromatographies of $L$. confusa (A), L. japonica(B) and standard mixture (C). Column: YMC-Pack Pro C18 $(5 \mu \mathrm{m}, 4.6 \mathrm{~mm}$ $\times 150 \mathrm{~mm}$ ); temperature of $25^{\circ} \mathrm{C}$; DAD detector. Peaks: 1 , chlorogenic acid; 2, sweroside; 3, luteolin 7-0-glucoside; 4, (E)-aldosecologanin; a, unknown at $13.8 \mathrm{~min} ; \mathrm{b}$, unknown at 20.6 min; c, unknown at 36.9 min.

\section{Analysis of cpDNA trnL-trnF region}

As a result of analyzing trnL-trnF regions of Lonicerae Flos including whole trnL intron of 944-958 bp, 3' exon of trnL gene of $44 \mathrm{bp}$ and $\operatorname{trn} L-\operatorname{trn} F$ intergenic spacer of 671-707 bp. L. japonica exhibited a length of $947 \mathrm{bp}$ and $L$. confusa exhibited one of $957 \mathrm{bp}$. Therefore, as a result of analyzing DNA sequences of both $L$. confusa and $L$. japonica, a total of 12 sequence gap (192 bp, 667-671 bp, 736-741 bp) were identified, and were shown to have $98 \%$ homology (Fig. 3). Two species were analyzed for their GC content. The result showed that the GC content of L. japonica was $35.8 \%$, and the GC content of L. confusa was $35.2 \%$.

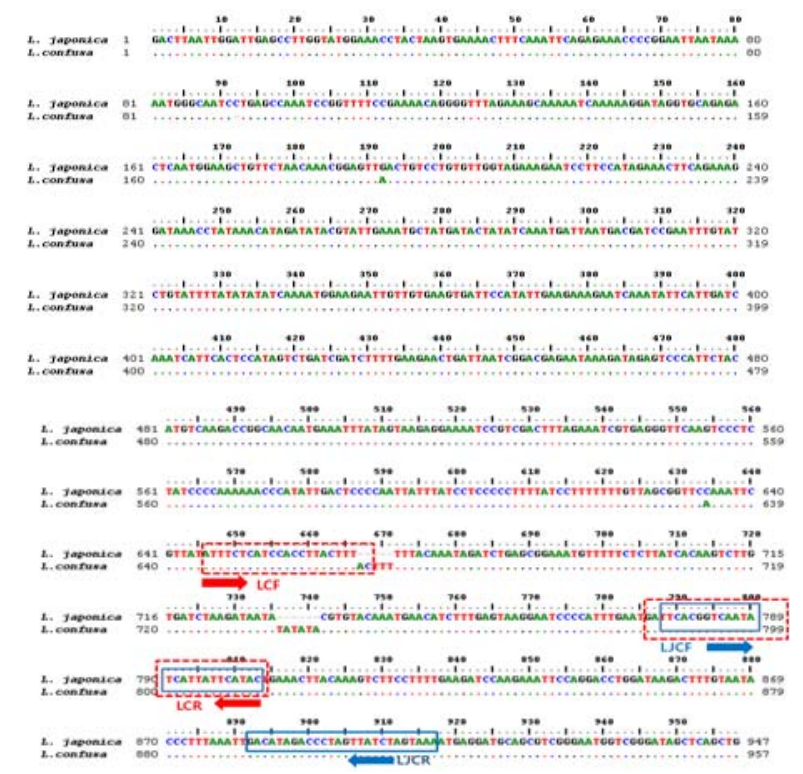

Figure 3. Aligned sequences of the $\operatorname{trn} L-t r n F$ regions in chloroplast DNA. Boxes indicate the position of LJC primers and LJC primers for $L$. japonica and $L$. confusa. Hyphens are gaps required for alignment. Dots in the sequences denote the same nucleotide state as the sequence of $L$. japonica.

\section{Detection of LC molecular genetic marker}

In order to design markers that distinguish between L. japonica and L. confusa, an LCF/LCR primer pair that is amplified at $164 \mathrm{bp}$ in L. confusa, but not so in L. japonica, was identified. The LCF/LCR primer pair was designed to be $L$. confusa specific, based on trnL-trnF sequences, and was confirmed to effectively distinguish $L$. japonica from L. confusa. At 130 bp, an internal LJCF/LJCR primer pair was amplified to be present in both L. japonica and L. confusa (Fig. 4). As a results, the listed samples were monitored using the specific band of $164 \mathrm{bp}$ size for its identification (Table 5). Thus, $L$. japonica and $L$. confusa were accurately distinguished using specific primer in trnL-trnF region.

Table 5. Identification results of $L$. japonica and $L$. confusa using designed molecular marker

\begin{tabular}{cccccc}
\hline No. & $\begin{array}{c}\text { Specific } \\
\text { Band } \\
(164 \mathrm{bp})\end{array}$ & $\begin{array}{c}\text { Identification } \\
\text { Results }\end{array}$ & No. & $\begin{array}{c}\text { Specific } \\
\text { Band } \\
(164 \mathrm{bp})\end{array}$ & $\begin{array}{c}\text { Identification } \\
\text { Results }\end{array}$ \\
\hline \hline 1 & - & L. japonica & 20 & - & L. japonica \\
2 & - & L. japonica & 21 & - & L. japonica \\
3 & - & L. japonica & 22 & - & L. japonica \\
4 & - & L. japonica & 23 & - & L. japonica \\
5 & - & L. japonica & 24 & - & L. japonica \\
6 & - & L. japonica & 25 & - & L. japonica \\
7 & - & L. japonica & 26 & - & L. japonica \\
8 & - & L. japonica & 27 & - & L. japonica \\
9 & - & L. japonica & 28 & + & L. confusa \\
10 & - & L. japonica & 29 & + & L. confusa \\
11 & - & L. japonica & 30 & + & L. confusa \\
12 & - & L. japonica & 31 & + & L. confusa \\
13 & - & L. japonica & 32 & + & L. confusa \\
14 & - & L. japonica & 33 & + & L. confusa \\
15 & - & L. japonica & 34 & + & L. confusa \\
16 & - & L. japonica & 35 & + & L. confusa \\
17 & - & L. japonica & 36 & + & L. confusa \\
18 & - & L. japonica & 37 & + & L. confusa \\
19 & - & L. japonica & & & \\
\hline
\end{tabular}
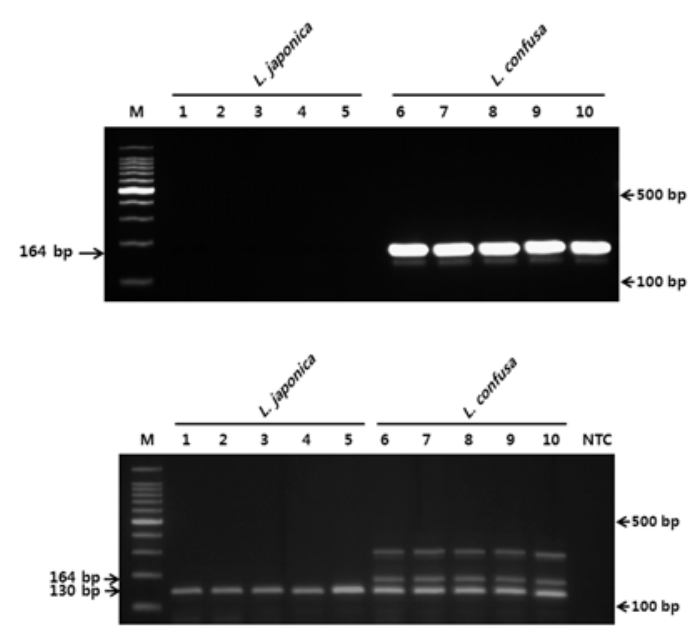

Figure 4. PCR products using species-specific primer designed from $L$. japonica and $L$. confusa $(A)$ and multiplex PCR products using the primer pairs designed from $L$. japonica and $L$. confusa (B) (lane 1-5; number 1 3, 7 8 of Table 1, lane 6-10; number 28 30, 33 34 of Table 1, NTC; no template control, M; $100 \mathrm{bp}$ DNA ladder). 


\section{Discussion}

In quality assessment of $L$. japonica by HPLC, luteolin 7-O-glucoside was proposed as an index compound $^{17)}$. However, luteolin $7-\mathrm{O}$-glucoside is an inappropriate marker as it is also detected in $L$. confusa and shows a significant deviation among samples. Previously, chlorogenic acid has been used as the chemical marker for the quality evaluation of Lonicerae Flos, owing to its antipyretic and antibiotic property as well as its high content in the herb. However, chlorogenic acid alone could not be responsible for the overall pharmacological activities of Lonicerae Flos. Chlorogenic acid has also been used as the chemical marker for other herbal drugs such as Chrysanthemi Flos $^{18)}$. By comparing the overall HPLC profiles of the different samples from Lonicera spp., we found it possible to distinguish clearly the two species in terms of the occurrence and/or relative concentration of iridoid glucosides. L. japonica has sweroside as the major iridoid glucosides. A variety of physiologically active compounds (such as luteolin, chlorogenic acid) has been found presented in $L$. confusa. Chlorogenic acid is the main effective constituent in L. confusa. Because all four constituents in the crude drugs contains nearby phenolic hydroxyl groups that was employed for their sensitive and selective detection. Therefore, other compounds should also be considered as one of the markers for quality control of Lonicerae Flos. In the comparative analysis between $L$. japonica and $L$. confusa using HPLC-DAD after selection of four index compounds of derived from $L$. japonica, Sweroside and (E)-aldosecologanin were only detected in L. japonica and are likely to be used as a discrimination marker

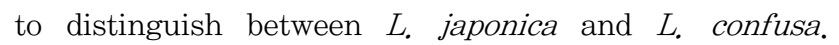
The results of this study were consistent with results of a previous study by $\mathrm{Li}$ et al. ${ }^{19)}$ on the development of HPLC methods used to determine the biological origin of Lonicerae Flos using iridoid glucosides such as 7-epi-loganin, sweroside, loganin, 7-epi-vogeloside, and secoxyloganin.

In phylogenetic tree analysis of Lonicerae Flos, the plant was divided into the groups of L. japonica and L. confusa (Data not shown). The differentiation between $L$. japonica and $L$. confusa was investigated through the $\operatorname{trn} L-\operatorname{trn} F$ region. When the nucleotide sequences of the trnL-trnF region were analyzed in phylogenetic tree, it was divided into two major groups based on genotype classification, though its place-of-origin was not confirmed. The results of homology analysis using the sequences of each sample from L. japonica showed more than 98\% homology.
Thus, this result confirmed that a homology percentage of inter-species nucleotide sequences exceeded $100 \%$ for $L$. confusa, the with no sequence variations between individuals identifiable from the samples in this study. However, the variations of base sequences between individuals are likely to be confirmed if more samples, collected from different locations, are analyzed. The analysis of sequence variation in the cpDNA has recently become an effective method of identification of medicinal herbs, and was applied in this case because the discrimination of $L$. japonica from its adulterants is currently limited to methods of morphology and chemical fingerprinting ${ }^{20)}$. In addition, when PCR analysis was performed on herbal medicines available in the market, using molecular genetic markers which were designed based on cpDNA, $L$. japonica and $L$. confusa were also distinguished by the amplified $164 \mathrm{bp}$ band. Therefore, L. japonica and $L$. confusa were effectively distinguished from one another by using a molecular genetic method.

\section{Conclusion}

We attempted to discriminate objectively both $L$. japonica and $L$. confusa using the chemical marker and genetic marker. The results are as follows.

1) This HPLC-DAD method is very suitable for identification between $L$. japonica and $L$. confusa when Sweroside is chosen as chemical marker. Thus, by means of chemical evidence we could rapidly clarify the botanical origin of these crude herbs. Furthermore, it will hopefully be employed to Sweroside within the genus, and within other medicinal plants.

2) The genetic marker obtained by DNA analysis will be useful as an important discrimination standard that can complement current laboratory tests.

3) A combination of the coupled methods would be the ideal in providing confirmative identification and assessment of $L$. japonica.

\section{Acknowledgement}

This research was supported by a grant from Korea Institute of Oriental Medicine (Grant No. K12080) and a grant (09112KFDA890) from Korea Food \& Drug Administration in 2010.

\section{References}

1. Park E, Kum S, Wang C, Park SY, Kim BS, 
Schuller-Levis G. Anti-inflammatory Activity of Herbal Medicines: Inhibition of Nitric Oxide Production and Tumor Necrosis Factor $-\alpha$ Secretion in an Activated Macrophage-like Cell Line. Am J Chin Med. 2005 ; 33 : 415-24.

2. Li F, Yuan B, Xiong Z, Lu X, Qin F, Chen H, Liu $\mathrm{Z}$. Fingerprint analysis of Flos Lonicerae japonicae using binary HPL Cprofiling. Biomed Chromatogr. $2006 ; 20: 634-41$.

3. Yoo HJ, Kang HJ, Song YS, Park EH, Lim CJ. Anti-angiogenic, antinociceptive and anti-inflammatory activities of Lonicera japonica extract. J Pharm Pharmacol. 2008 ; 60 : 779-86.

4. Ryu KH, Rhee HI, Kim JH, Yoo H, Lee BY, Um KA, Kim K, Noh JY, Lim KM, Chung JH. Anti-inflammatory and analgesic activities of SKLJI, a highly purified and injectable herbal extract of Lonicera japonica. Biosci Biotechnol Biochem. 2001 ; 74 : 2022-8.

5. Committee of National Pharmacopoeia : Pharmacopoeia of People's Republic of China, Press of Chemical Industry. CP, Beijing China. $2005: 21-2$.

6. Korea Food and Drug Administration : the Korean Pharmacopoeia(KP) IX(9 ${ }^{\text {th }}$ ed.).Seoul : KFDA. 2007 : 914.

7. Yang H, Yuan B, Li L, Chen H, Li F. HPLC determination and pharmacokinetics of chlorogenic acid in rabbit plasma after an oral dose of Flos Lonicerae extract. J Chromatogr Sci. 2004 ; 42 : $173-6$.

8. Lu HT, Jiang Y, Chen F. Application of preparative high-speed counter-current chromatography for separation of chlorogenic acid from Flos Lonicerae. J Chromatogr A. $2004 ; 1026$ : 185-90.

9. Chen J, Song Y, Li P. Capillary high-performance liquid chromatography with mass spectrometry for simultaneous determination of major flavonoids, iridoid glucosides and saponins in Flos Lonicerae. J Chromatogr A. 2007 ; 1157 : 217-26.

10. Machida K, Sasaki H, Iijima T, Kikuchi M. Studies on the constituents of Lonicera species. XVII. New iridoid glycosides of the stems and leaves of Lonicera japonica THUNB. Chem Pharm Bull. 2002 ; $50: 1041-4$.

11. Lee EJ, Lee JY, Kim JS, Kang SS. Phytochemical Studies on Lonicerae Flos(1)-Isolation of Iridoid Glycosides and other Constituents. Natural Product Sciences. $2010 ; 16: 32-8$.

12. Chai XY, Li SL, Li P. Quality evaluation of Flos lonicerae through a simultaneous determination of seven saponins by HPLC with ELSD. J Chromatogr A. $2005 ; 1070: 43-8$.

13. Lin LM, Zhang XG, Zhu JJ, Gao HM, Wang ZM,
Wang WH. Two new triterpenoid saponins from the flowers and buds of Lonicera japonica. J Asian Nat Prod Res. 2008 ; 10 : 925-9.

14. Fan LL, Zhu S, Chen HB, Yang DH, Cai SQ, Komatsu K. Molecular analysis of Stemona plants in China based on sequences of four chloroplast DNA regions. Biol Pharm Bull. 2009 ; 32(8) : 1439-46.

15. Choi CW, Jung HA, Kang SS, Choi JS. Antioxidant constituents and a new triterpenoid glycoside from Flos Lonicera. Arch Pharm Res. 2007 ; 30(1) : 1-7.

16. Taberlet P, Gielly L, Pautou G and Bouvet J. Universal primers for amplification of three noncoding regions of chloroplast DNA. Plant Molec Boil. $1991 ; 17$ : 1105-09.

17. Na MK, Huong HTT, An RB, Lee SM, Kim YH, Lee JP, Seong RS, Lee KS, Bae KH. Quality evaluation of Lonicerae Flos. Korean $J$ Pharmacogn. $2000 ; 31: 340-4$.

18. Yao X, Jiang G, Chen G. Determination of active constituents in Lonicera confusa DC. by capillary electrophoresis with amperometric detection. Biomed Chromatogr. 2000 ; 20 : 1192-9.

19. Li HJ, Li P, Ye WC. Determination of five major iridoid glucosides in Flos Lonicerae by high-performance liquid chromatography coupled with evaporative light scattering detection. J Chromatogr A. 2003 ; $1008: 167-72$.

20. Peng X, Li W, Wang W and Bai G. Identification of Lonicera japonica by PCR-RFLP and allele-specific diagnostic PCR based on sequences of internal transcribed spacer regions. Planta Med. 2010 ; 76 : 497-9. 